\title{
A tribute to Otto Ludwig Lange (1927-2017)
}

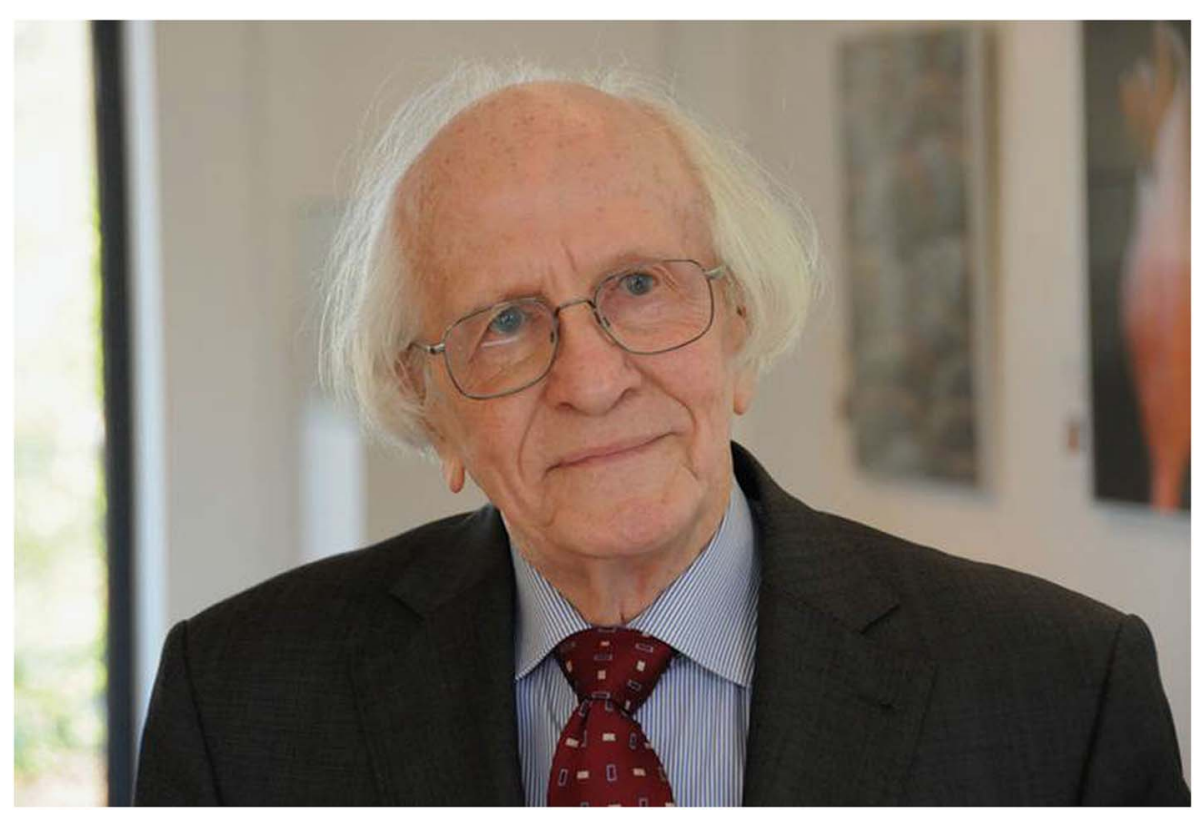

When one thinks of lichen ecophysiology then the name Otto Lange comes immediately to the fore. In the past decades, from the 1950 s, our knowledge and understanding of the ecophysiology of lichens has increased massively and at the centre of these developments was Otto Lange.

Otto was, in fact, a plant and lichen ecophysiologist and over half of his publications are devoted to higher plants. However, lichens were always his first love and he pursued his interest in them through his entire life. In Otto's own words: "the objective of physiological plant ecology is to explain processes in plant ecology, such as plant performance, survival, and distribution, in physiological, biophysical, and biochemical terms. Thus, it was the first aim of my research to quantitatively analyse responses of plants in nature with respect to their environmental conditions". A major characteristic of his research from the very beginning was the way in which he combined analysis under controlled conditions in the laboratory with measurements and experimentation in the field under as near natural conditions as experimentally possible. Other characteristics, and the ones which really led to Otto being accepted as the leader in this field, were his excellence in research, his care and accuracy, his drive to develop cutting edge technology, and his scholarship and collegiality, both of the latter at the highest level.

Otto's research career started soon after the end of the Second World War; Germany at that time was effectively destroyed so that research conditions were far from satisfactory. He started, therefore, with studies that did not require complex equipment but did need excellence in experimentation and a clear vision of the aims. These were detailed investigations into the heat and cold tolerance of lichens and plants generally. He often 
mentioned how thankful he was to have been supported by the Marshall Plan in order to buy a mirror galvanometer for accurate temperature measurements. His first major paper (1953) showed that dry lichens (over 30 species from 23 different sites across Europe) could withstand temperatures above $70{ }^{\circ} \mathrm{C}$, up to $101^{\circ} \mathrm{C}$. In a later study (1966) he showed that hydrated lichens rarely survived above $35^{\circ} \mathrm{C}$ (a lower temperature than most higher plants) and from this contrast, between hydrated and dry, he drew attention to the protective effects of the poikilohydric lifestyle. A survey of the low temperature limits of 30 species revealed a lower limit of $-24^{\circ} \mathrm{C}$, somewhat surprisingly for a lichen from sand dunes on the North Sea coast. These papers are classics and only recently have some of the studies been repeated.

From the very start Otto decided that he would use $\mathrm{CO}_{2}$-exchange (net photosynthesis (NP) and respiration) as indicators of the functional status of lichens. In his first paper he used a colorimetric method that needs considerable skill to obtain repeatable results. He rapidly changed to using infra-red gas analyzers to measure $\mathrm{CO}_{2}$ exchange and his aim was always to improve these techniques to a point where they were not only accurate in the laboratory but they could also be used in the field. He achieved this aim through a career-long collaboration with Heinz Walz, who was initially at Siemens and then moved in 1972 to set up Heinz Walz $\mathrm{GmbH}$, a company that has remained a world leader for equipment to study photosynthesis. The relationship resulted in the development of fully conditioned cuvettes (temperature, $\mathrm{CO}_{2}$ concentration, humidity and light could be controlled) for monitoring photosynthesis and transpiration which could also be used in the field. Small $\mathrm{H}_{2} \mathrm{O}$ / $\mathrm{CO}_{2}$ porometers were developed that allowed rapid measurements on leaves and lichens. In 1990, Otto and Heinz Walz $\mathrm{GmbH}$ were awarded the Adalbert-Seifriz Prize for technology transfer in the area of ecophysiological instrumentation. These techniques were adopted as standard by many other researchers throughout the world.
Otto's interest and skills in temperature effects and $\mathrm{CO}_{2}$ exchange meant that Vernon Ahmadjian invited him to assist with the first gas exchange measurements of lichens in the field in Antarctica by the USA research team at Cape Hallett, Northern Victoria Land in 1966. Although Otto never returned to Antarctica, one of his research assistants at Würzburg, Ludger Kappen, became the world leader in photosynthetic studies of Antarctic lichens and was later leader of the Institut für Polarökologie an der Universität Kiel.

By 1970 Otto had a mobile system that allowed gas exchange to be measured in the field and he used his mobile laboratory to investigate $\mathrm{CO}_{2}$-exchange of plants and lichens in the Negev Desert, Israel. His studies on the photosynthetic activity of Ramalina maciformis (his favourite lichen by far) in the Negev Desert are classics and his figure showing early morning gulp of photosynthesis is probably one of the best-known results in lichen ecophysiology. Ernst-Detlef Schulze was one of Otto's doctoral students at this time and went on to be head of the Max-Planck Institut für Biogeochemie. One of Otto's earliest results in the Negev was to show that $R$. maciformis could regain positive net photosynthesis by hydration from humid air alone. This topic became a life-long interest for him and he demonstrated that this was a property possessed by green algal lichens but not cyanobacterial species. It is now clear that this hydration by humid air is not just a laboratory artefact but has many ecological implications. Otto extended this work to other biomes including Alaskan tundra, New Zealand rainforest, Portugal, Namibia and the Panamanian tropical forest.

Another life-long interest was analysis of the influence of environmental and lichen factors (light, temperature and thallus water content) on net photosynthesis in lichens. His publications on individual species, such as Teloschistes capensis, are spectacular combinations of the effects of individual factors on NP and respiration combined with monitoring of $\mathrm{CO}_{2}$-exchange over several days. One gets a complete view of the lichens' behaviour. One feature of lichen NP that 
particularly fascinated Otto was the decrease in net photosynthesis at high thallus water contents, the so-called suprasaturation effect, that was shown by some species. Otto showed by measurements at high $\mathrm{CO}_{2}$ concentrations that this depression was most likely due to increased diffusion resistances caused by water blockage at high water contents. However, because the diffusion of water vapour and $\mathrm{CO}_{2}$ do not follow the same pathways in lichens, it is not possible to determine $\mathrm{CO}_{2}$ diffusion resistances using the techniques from higher plants. Otto solved this problem elegantly by measuring the response of NP to water content in both normal air ( $80 \%$ nitrogen, $20 \%$ oxygen) and helox (the nitrogen is replaced by helium). $\mathrm{CO}_{2}$ diffuses at different rates in nitrogen and helium and, by suitable modelling carried out by Ian Cowan who developed the equations used in modern stomatal studies, this allows the resistances to be measured. By no means was this as straightforward as it first appears. Almost all the instruments (flow meters, infra-red gas analyzers) have different responses in the two gases and getting a gastight system with helox was a nightmare. It took months of preparation but the measurements were successful and this remains the only exact determination of diffusion resistances in lichens. From these results, major conclusions could be drawn about the effects of thallus construction on gas exchange rates in lichens and it became obvious that thallus morphology and anatomy are major influences on the ecological performance of lichens.

Otto made many studies of the influences of environmental factors on lichens, his goal being to obtain accurate estimates for the annual carbon gain of lichens. He achieved this after his retirement in the early 1990s when he developed the so-called Klappcuvette. This system automatically measured lichen $\mathrm{CO}_{2}$-exchange together with all environmental factors every 30 minutes. He studied several lichen species and obtained data sets that were many months in length, and some were over a year. By integrating the 30 minute measurements he was able to produce the first solid estimates of annual carbon gain for lichens in their natural environment. By utilizing information from laboratory studies, it was possible to determine what was limiting NP and also, by categorizing the days, he could discover which weather conditions were important. The data sets allowed many major discoveries to be made but two important results stand out. The first was that suprasaturation has a major impact on carbon gain. Lichens without it, such as Cladonia convoluta, have high net photosynthetic rates under very wet conditions (heavy rain) whilst species such as Lecanora muralis, which have a very severe suprasaturation depression, made very little carbon gain under these conditions. The latter species made most use of early morning dew events. Second, deeper analysis of the data sets also revealed that some species changed the response of NP to temperature according to the season of the year. It was found that some lichens could fully acclimate their respiration to temperature so that carbon loss was reduced in warmer months.

Following a sabbatical leave with Jayne Belnap at Utah in 1985, Otto became very interested in soil crusts. Together with Jayne, he published, "Biological Soil Crusts: Structure, Function and Management" (Ecological Studies, Volume 150, 2001) which effectively became the bible for soil crust studies and underpinned a massive resurgence internationally in studies on the ecology and performance of soil crusts. As a result, soil crusts have moved from being almost unknown to a major research field. Today we understand that biological soil crusts were apparently the first terrestrial ecosystem on Earth, as early as 2500 million years ago, and still play an important role in all major terrestrial biomes where the abundance of vascular plants is limited. With their advent, lichens became an integral part of biological soil crusts and shape the characteristic habit of these communities.

Otto built collaborations with other researchers throughout the world and also locally in Würzburg. His collaboration with Botanik I, with Ulrich Heber (its leader) and Ulrich Schreiber, resulted in the development 
of the PAM fluorescence technique which now dominates photosynthesis research. In 1986 Otto and Ulrich Heber received the Gottfried-Wilhelm-Leibniz Prize from the Deutschen Forschungsgemeinschaft as a recognition of their contribution to photosynthetic studies.

Although we see Otto as a lichenologist he was also a major force in studies on higher plant ecophysiology. Approximately half of his publications are on higher plants and his work included important studies such as the first demonstration that humidity influenced stomatal opening in leaves, on factors influencing leaf temperature in desert plants, and a major study on forest decline in the Germany.

Topics mentioned here represent only a part of Otto's productivity. In all he published 382 papers and was Founding Editor and Chief Editor of the Springer series, Ecological Studies, with 230 volumes completed. He was also Editor or co-editor for Oecologia (1970-2007), Flora (since 1964), Trees (1986-1998), Photosynthetica (19671995) and Botanica Acta (1987-1991). His skill as an editor cannot be underestimated.

Otto was born on 21st August, 1927 in Dortmund but spent his school years in Göttingen. Like many at that time at the age of 16 he was drafted into military service and, as a result, is probably the only lichenologist who started their career as a prisoner of war. I mention this detail because these events affected him greatly and led to him being an activist against war and to later interests in research in Israel with Michael Evanari. Between 1946 and 1952 he studied at Göttingen University and graduated with Dr. rer. Nat. with a dissertation entitled "Heat and desiccation resistance of lichens as related to their distribution" supervised by Prof. Dr. Franz Firbas. In 1959 he received his Habilitation, a necessary step to gain higher positions in German universities with a thesis entitled "Investigations on temperature relations and heat resistance of desert and savannah plants in Mauritania". He became a full Professor at Göttingen in 1963 and moved to the University of Würzburg in 1967 where he set up the Botanic II department and was
Head of the Botanic Garden. Other universities tried to tempt him away, the so-called Ruf, but he remained at Würzburg until retirement as Emeritus Professor in 1992.

Otto received many honours as befits such a successful research life. Those particularly relevant to lichenologists are his Honorary life membership of the British Lichen Society (1991), the award of the Acharius Medal of the International Association for Lichenology (1992), and three lichen species bear his name (Peltula langei, Hubbsia langei and Fackelixia ottolangei). He received, in 2009, the award of Eminent Ecologist from the Ecological Society of America, the first person from outside the USA to receive this. Not to be forgotten, and Otto's favourite, is Lange Peak, a $2435 \mathrm{~m}$ high mountain in the Lyttelton Range, Admiralty Mountains, Antarctica, awarded for his research at Hallett Station, 1966. In addition to these were: 1972 Member, "Deutsche Akademie der Naturforscher, Leopoldina" (German Academy for Scientists, Leopoldina); 1974 Antarctic Service Medal, awarded by the United States Government; 1978 Member, "Bayerische Akademie der Wissenschaften, München" (Bavarian Academy of Science, Munich); 1984 Bundesverdienstkreuz I. Klasse des Verdienstordens der Bundesrepublik Deutschland (Order of Merit 1st class, awarded by the Fed. Rep. of Germany); 1986 Gottfried Wilhelm Leibniz-Preis der Deutschen Forschungsgemeinschaft (together with Prof. Heber, Würzburg); 1988 Balzan Prize for "Applied Botany including Ecology" (together with Prof. Michael Evanari) presented by the Italian President, Francesco Cossiga in Rome; 1989 Member, "Academia Europaea", London; 1991 Bayerischer Maximiliansorden für Wissenschaft und Kunst der Abteilung für Wissenschaft (Bavarian Maximilian Order for Science and Art); 1992 Honorary Member of "Gesellschaft für Mykologie und Lichenologie" (Association for Mycology and Lichenology); 2016 Career Achievement Award by the international Biological Soil Crust research Community, Moab, Utah, USA.

A list of publications and more information about Otto's honours and awards can be 
found in the publication celebrating his 80th birthday by Burkhard Büdel (Flora 202: 590 607, 2007)).

Otto is survived by his wife, Rose, and their two daughters, Annette and Ulrike. Rose was, in fact, a co-author of one of the first papers by Otto. In his early years he published most papers as a single author, something rather rare nowadays.
Otto passed away peacefully on 14th August, 2017, after a sudden and unexpected illness. His passing was a shock to everyone and he will be greatly missed but remembered as a great lichenologist.

T. G. Allan Green 